\title{
Pneumoconiosis and emphysema in construction workers: results of HRCT and lung function findings
}

\author{
E Meijer, ${ }^{1}$ E Tjoe Nij, ${ }^{1}$ T Kraus, ${ }^{2}$ J S van der Zee, ${ }^{3} 0$ van Delden, ${ }^{3} \mathrm{M}$ van Leeuwen, \\ J W Lammers, ${ }^{4}$ D Heederik ${ }^{1}$
}

${ }^{1}$ Utrecht University, Institute for Risk Assessment Sciences, Division of Environmental Epidemiology, Utrecht, The Netherlands

Institute and Outpatient Clinic for Occupational and Social Medicine, University Hospital, RWTH Aachen University, Aachen, Germany ${ }^{3}$ Department of Pulmonology, Academic Medical Center, Amsterdam, The Netherlands ${ }^{4}$ Department of Pulmonary Diseases, University Medical Center, Utrecht, The Netherlands

\section{Correspondence to} E Meijer, Institute for Risk Assessment Sciences, Division of Environmental Epidemiology, Utrecht University, PO Box 80178, Utrecht 3508 TD, The Netherlands; e.meijer@uu.nl

Accepted 14 January 2011 Published Online First 25 February 2011

\section{ABSTRACT}

Objectives To evaluate the prevalence of HRCT findings in construction workers previously surveyed by chest radiographs classified according to ILO guidelines. To examine the association between HRCT findings and exposure to quartz containing dust, and lung function. Methods The study comprised a questionnaire, dynamic and static lung function measurements, single-breath $\mathrm{CO}$ diffusion capacity, chest radiographs and HRCT in 79 individuals. Certified ' $\mathrm{B}$ ' readers coded radiographs according to the ILO classification. HRCT scans were read according to an international classification system. A qualitative exposure index for cumulative respiratory quartz on a 10-point scale was used.

Results Agreement between HRCT readers was good $(\kappa>0.60)$, except for irregular opacities $(\kappa=0.23)$. In ILO category 0/0, 8\% HRCT round, 22\% irregular and/or linear opacities and $41 \%$ HRCT emphysema was found. HRCT round opacities was associated with high cumulative quartz exposure (OR 7.1; 95\% Cl 1.3 to 37.8). Emphysema was associated with smoking (OR 10.1; 95\% Cl 1.2 to 84.2) and showed a reduction in $T_{L, C 0, s b}$ HRCT round opacities was not associated with lung function. Current smoking was negatively associated with $F E V_{1} / F V C$ ratio and positively with $\mathrm{RV} / \mathrm{TLC}$ ratio, and showed a reduction in $T_{L, C 0, s b}(13.4 \%)$, adjusted for different HRCT findings.

Conclusions Low grade silicosis cannot be excluded in workers with normal chest radiographs (ILO 0/0). In relatively highly exposed construction workers, a sevenfold increased risk of simple (nodular) silicosis was found. Emphysema on HRCT was associated with current or former smokers, but not with exposure, and contributed to reduced diffusion capacity. Airflow limitation was mainly determined by current smoking and was not associated with simple (nodular) silicosis.

\section{INTRODUCTION}

Identification of pneumoconiosis (silicosis) at a population level in workers exposed to silica containing dust has until recently been carried out by conventional chest radiographs, classified according to the International Labour Organization (ILO) guidelines. ${ }^{1}$ In a study among 1335 Dutch construction workers, we observed radiological changes in $2.9 \%$ of ILO profusion category $\geq 1 / 1 .{ }^{2}$ Silicosis (defined as the presence of small rounded opacities) was reported on $10(0.8 \%)$ chest radiographs. The study showed an association between the prevalence of ILO $\geq 1 / 1$ and cumulative exposure to quartz containing dust. However, in the minor profusion categories $0 / 1$ and $1 / 0$,

\section{What this paper adds}

- A few studies have evaluated the association of high-resolution CT (HRCT) lung findings with quartz exposure.

- The association of (low grade) silicosis with reduced lung function is often not adjusted for emphysema.

- This study showed that HRCT well defined round opacities, consistent with low grade (nodular) silicosis, are associated with cumulative quartz exposure.

- We found no reduction in lung function in workers with low grade (nodular) silicosis independent of emphysema or being a current smoker.

- We found a substantial effect of current smoking on bronchial obstruction and a reduced diffusion capacity associated with emphysema.

a poor agreement between the three certified ' $\mathrm{B}$ ' readers ( $\kappa$ between 0.21 and 0.4 ) was reported.

This was the rationale for a follow-up study in a sample of construction workers using more advanced techniques. High-resolution CT (HRCT) has been shown to be superior to chest radiography for the detection of small opacities, interstitial fibrosis and emphysema, especially in low grade pneumoconiosis. ${ }^{3-5}$ Posterior-anterior chest radiographs, dynamic and static lung volumes and gas diffusion parameters were also measured in all participating individuals.

The aim was to explore the distribution of different HRCT findings in a sample of construction workers with low grade pneumoconiosis re-examined in 2002. A second aim was to investigate exposure to quartz containing dust and lung function associated with the HRCT findings.

\section{METHODS}

\section{Study population and study design}

Of 1335 construction workers examined in 1998 , 180 with different stages on chest radiographs were re-invited in 2002 for more extensive investigations including HRCT. The sample was taken according to the initial distribution of ILO categories in the original study. Of the 180 invited workers, 41 declined the invitation and 43 did not reply, resulting in 96 individuals. The workers received a letter of invitation, information about the study and an informed consent form. All were Caucasian 
and male. Most of the individuals were still working in the construction industry or had recently stopped working (pensioned or incapacitated for work: 12/96; 13\%) or changed occupation (5/96; 6\%). Due to budgetary constraints, a maximum of 79 HRCT scans was set, resulting in 79 workers invited according to the date of response to the invitation letter.

The study protocol comprised a detailed questionnaire, dynamic and static lung function measurements including reversibility and single-breath $\mathrm{CO}$ diffusion capacity, posterior-anterior chest radiographs and HRCT scans. All tests were performed on the same day. Examinations took place in the University Medical Centre in Utrecht (UMCU) and the Academic Medical Center in Amsterdam (AMC). Lung function measurements and radiological procedures in the two study centres were harmonised. The medical ethics committees of the AMC and UMCU approved the study. Diagnostic data were anonymised by the removal of any personal identification marks. Informed consent was obtained from each individual worker and included the agreement that personal information could be used for health surveillance purposes and results could be published in international journals.

\section{Questionnaire}

The self-administered questionnaire comprised items on occupational history, smoking habits and a validated questionnaire on respiratory health. ${ }^{6}$ Smoking habits were categorised into never, ever and current smokers. Smoking intensity was considered constant over time.

\section{HRCT}

HRCT scans (about 24 scans per person) of the chest were obtained during full inspiration, with the individual in a supine position. A $1 \mathrm{~mm}$ slice was scanned every $10 \mathrm{~mm}$. In addition, about five scans were taken during expiration. A standard highresolution algorithm HRCT protocol was used $(140 \mathrm{kV}$, $175 \mathrm{~mA})$. In the UMCU, HRCT scans were obtained with a Tomoscan AV (SR 7000, Philips, Eindhoven, the Netherlands) and in the AMC with a MX-Twin RTS (Marconi, Cleveland, Ohio, USA) or a Mx8000 scanner (Philips, Best, The Netherlands). The HRCT scans were read independently by three trained readers (one occupational physician (TK) and two radiologists in Germany) according to an international classification system. ${ }^{7} 8$ Readers were blinded for data such as age, smoking habits and exposure status. Consensus by at least two of the three readers for the specific presence of well defined rounded opacities, irregular and/or linear opacities, ground glass opacities, honeycombing, emphysema, large opacities, pleural abnormalities (visceral and parietal type) and pleural calcifications was used as the measure of outcome. For data analysis, no distinction was made regarding size, location or sum grade of round and irregular opacities, or for the extent, localisation or width of pleural changes. Pleural abnormalities were classified as parietal or visceral. Emphysema was defined as sharply delineated low-density areas subdivided into acinar, panlobular, subpleural or cicatricial types in both lungs. Pleural calcifications were regarded as non-specific late reactions of the parietal and visceral pleura. Honeycombing was not found to be present.

\section{Chest radiographs}

Hard copies $(40 \times 40 \mathrm{~cm})$ were made of digital posterior-anterior chest stored radiographs in the AMC and UMCU hospital. All films were read independently in the USA by two certified ' $\mathrm{B}$ ' readers according to the ILO classification. ${ }^{1}$ In case of disagreement, a third ' $\mathrm{B}$ ' reader was consulted. The ILO classification schema was used to record, in particular, the profusion and type of small opacities and the presence of pleural thickenings and pleural plaques. Scores of profusion were always the same or only one subclass apart. We used three profusion categories $(0 / 0$, $01-1 / 0$ and $\geq 1 / 1$ ) for the analyses.

\section{Lung function}

Lung function was measured with a pneumo-tachometer (Masterscreen Pneumo, Jaeger Benelux, Utrecht, the Netherlands), according to the recommendations of the European Respiratory Society (ERS). ${ }^{9}$ Reversibility of bronchial obstruction was considered if forced expiratory volume in $1 \mathrm{~s}\left(\mathrm{FEV}_{1}\right)$ increased by more than $12 \%$ within $20 \mathrm{~min}$ after inhalation of $500 \mu \mathrm{g}$ salbutamol. Total lung capacity (TLC) was determined in a body plethysmograph (ASC type, Jaeger Benelux). Diffusion capacity was determined by the single-breath carbon monoxide transfer factor $\left(\mathrm{T}_{\mathrm{L}, \mathrm{CO}, \mathrm{sb}}\right)$ using a rolling seal spirometer (MS Closed System, Jaeger Benelux). Lung function data were compared with the European Respiratory Society reference values. We used percentage predicted to compare the actual with the reference lung function levels. ${ }^{9}$

\section{Exposure}

Three industrial hygienists ranked past and present occupations in the construction industry on a 10-point scale (low 0; high 10). Repeated full-shift respirable quartz exposure measurements were available for 34 construction workers whose jobs mainly involved concrete drilling, removal of mortar between bricks, pointing, cleaning of construction sites, demolition and cleaning. These measurements were used by the hygienists to calibrate their assessment. The resulting semi-quantitative exposure metric was used to estimate cumulative quartz exposure by multiplying duration of exposure by the individual's exposure index to obtain a cumulative exposure index (CEI). ${ }^{10}$

\section{Data analysis}

All statistical analyses were performed with SPSS 15.0 for Windows. Prevalence rates were compared using the $\chi^{2}$ test (or Fischer's exact test). Differences between means were compared using the Student $t$ test or ANOVA. Cumulative quartz exposure levels were categorised in tertiles for dose-response analysis. Multiple logistic regression analysis was used to calculate odds ratios for the influence of exposure to quartz containing dust on the outcome variables. Analyses were

Table 1 General characteristics of 79 construction workers participating in a follow-up study

\begin{tabular}{|c|c|c|}
\hline & & $\mathbf{N}(\%)$ \\
\hline Age, mean (range) & & $49.6(35-67)$ \\
\hline Current smokers & & $41(52)$ \\
\hline Ex-smokers & & $24(30)$ \\
\hline Never smokers & & $14(18)$ \\
\hline $\begin{array}{l}\text { Years working in the construction } \\
\text { industry, mean (median) }\end{array}$ & & $21.2(21)$ \\
\hline CEl, mean $(\mathrm{SE})^{*}$ & & $10.7(1.0)$ \\
\hline \multicolumn{3}{|c|}{ Prevalence of median readings of chest radiographs according to ILO guidelines } \\
\hline & $1998, N=1294 \dagger$ & $2002, N=77 \ddagger$ \\
\hline Profusion category $0 / 0$ & $868(67 \%)$ & $63(82 \%)$ \\
\hline Profusion categories $0 / 1$ and $1 / 0$ & $389(30 \%)$ & $11(14 \%)$ \\
\hline Profusion category $\geq 1 / 1$ & $37(3 \%)$ & $3(4 \%)$ \\
\hline
\end{tabular}

*CEl: cumulative exposure index to respirable (silica) dust (=job weighted exposure index $\times$ years in the construction industry).

$\dagger 36$ radiographs of unacceptable quality were excluded.

$\ddagger$ (Two workers refused chest $x$-ray).

ILO, International Labour Organization. 
Table 2 Prevalence of high-resolution CT (HRCT) findings in construction workers with low grade pneumoconiosis according to International Labour Organization (IL0) classification ( $n=77$ )

\begin{tabular}{|c|c|c|c|}
\hline \multirow[b]{2}{*}{ HRCT results } & \multicolumn{3}{|c|}{ ILO classification } \\
\hline & $\begin{array}{l}\text { Profusion } \\
0 / 0(n=63)\end{array}$ & $\begin{array}{l}\text { Profusion } 0 / 1 \\
\text { and } 1 / 0(n=11)\end{array}$ & $\begin{array}{l}\text { Profusion } \\
\geq 1 / 1(n=3)\end{array}$ \\
\hline Well defined round opacities & $5(8 \%)$ & $4(36 \%)$ & $3(100 \%)$ \\
\hline Irregular and/or linear opacities & $14(22 \%)$ & $1(9 \%)$ & $1(33 \%)$ \\
\hline Emphysema & $26(41 \%)$ & $3(27 \%)$ & $0(0.0 \%)$ \\
\hline Ground glass opacity & $4(6 \%)$ & $1(9 \%)$ & $0(0.0 \%)$ \\
\hline Pleural abnormalities (visceral type) & $5(8 \%)$ & $1(9 \%)$ & $2(67 \%)$ \\
\hline Pleural abnormalities (parietal type) & $15(24 \%)$ & $4(36 \%)$ & $2(67 \%)$ \\
\hline Pleural calcifications & $5(8 \%)$ & $1(9 \%)$ & $2(67 \%)$ \\
\hline Normal HRCT & $22(34.9 \%)$ & $3(27.3 \%)$ & $0(0.0 \%)$ \\
\hline
\end{tabular}

adjusted for potential confounding by smoking, in which smoking was categorised as never and ever (including current smoking) smokers. Multiple linear regression was used to model the association between lung function (expressed as percentage predicted) and HRCT round opacities, irregular and/or linear opacities and emphysema. To adjust for the direct effect of smoking on airflow limitation and diffusion capacity, we included being a current smoker (or not) in the analysis. Statistical significance was reached at $\mathrm{p}<0.05$.

\section{RESULTS}

General characteristics, and the results of chest radiographs (ILO categories) at baseline (1998) and at follow-up (2002) are shown in table 1 . Workers were on average 49.6 years of age (range 35-67) and had worked on average for 21.2 years (median 21 years) in the construction industry. Fifty two per cent of the construction workers were current smokers. The prevalence of ILO category $0 / 0$ in the follow-up study was $82 \%$ and somewhat higher than at baseline. Profusion scores of $1 / 1$ or higher were found in $4 \%$ of workers at follow-up and $3 \%$ at baseline. Agreement between readers of HRCT scans $(n=79)$ was good for the presence of rounded opacities (overall $\kappa=0.69$ ), pleural changes (both visceral and parietal types) $(\kappa=0.61)$, pleural calcification $(\kappa=0.74)$ and emphysema $(\kappa=0.59)$, but low for the presence of irregular and/or linear opacities $(\kappa=0.23)$. Agreement between the two readers who read all 77 chest radiographs was also good for the presence of rounded opacities $(\kappa=0.68)$ and pleural changes $(\kappa=0.79)$ and poor for the presence of irregular opacities $(\kappa=0.14)$ (data not shown). The prevalence of HRCT findings in workers with low grade pneumoconiosis stratified according to ILO classification is shown in table 2 . In workers categorised as having ILO profusion $0 / 0,41 \%$ were detected on HRCT as having emphysema and $22 \%$ irregular and/or linear opacities. The association between pleural abnormalities of the parietal type and rounded opacities on the HRCT scan (nine pleural and three rounded; 69\%) was statistically significantly $\left(\chi^{2} 13.2 ;\right.$ df $\left.1 ; p=0.000\right)$ (data not shown).

Table 3 shows the associations between HRCT findings and cumulative exposure to silica containing dust adjusted for smoking (ever/never). The presence of well defined round opacities, irregular and/or linear opacities and emphysema was each analysed separately in logistic regression models. HRCT well defined round opacities were statistically significantly associated with high cumulative dust exposure (OR 7.1; 95\% CI 1.3 to 37.8). The presence of emphysema showed a strong association with ever smoking (OR 10.1; 95\% CI 1.2 to 84.2 ) but not with exposure. The models explained $22 \%$ and $27 \%$ of the variance, respectively, in the dependent variable by smoking and exposure, as calculated by Nagelkerke's pseudo $\mathrm{R}^{2}$. For irregular and/or linear opacities, a borderline statistical significance with high exposure levels (OR 4.0; 95\% CI 0.9 to 17.9) and no statistically significant association with smoking was found.

HRCT detected emphysema was found in $44.6 \%$ of construction workers who were smokers or had been smokers in the past. No emphysema was found in lifetime non-smokers. No difference in the prevalence of emphysema (44.6\% and $44.4 \%$, respectively) was found among individuals with or without round opacities who were current or ex-smokers (table 4). Never smokers showed a prevalence of $28.6 \%$ (4/14) of round opacities compared to $13.8 \%(9 / 65)$ in current and/or ex-smokers $\left(\chi^{2} 1.8\right.$; df $1 ; \mathrm{p}=0.18)$. In never smokers $14.3 \%(2 / 14)$ had irregular and/ or linear opacities compared to $23.1 \%(15 / 65)$ of current and/or ex-smokers ( $\chi^{2} 0.53$; df $1 ; p=0.47$ ) (data not shown).

Finally, the effect on lung function across different HRCT findings was evaluated by multiple linear regression analysis (table 5). Well defined round opacities were not associated with lung function including diffusion capacity $\left(\mathrm{T}_{\mathrm{L}, \mathrm{CO}, \mathrm{sb}}\right)$. Irregular and/or linear opacities were statistically significantly associated with forced vital capacity (FVC) and FEV 1 . However the FEV 1 / FVC ratio showed no association. $\mathrm{FEV}_{1}$ was negatively associated with emphysema. Current smoking was negatively associated with the $\mathrm{FEV}_{1} / \mathrm{FVC}$ ratio and positively associated with the residual volume (RV)/TLC ratio, both at a high statistical level. Diffusion capacity $\left(\mathrm{T}_{\mathrm{L}, \mathrm{CO}, \mathrm{sb}}\right)$ was negatively associated with irregular and/or linear opacities, emphysema and smoking. The model showed good explained variability for reduced diffusion capacity (34\%) attributable to irregular and/or linear opacities, emphysema and smoking together.

\section{DISCUSSION}

This study showed that, among construction workers, HRCT well defined round opacities, consistent with simple (nodular) silicosis, are associated with cumulative quartz exposure. Workers in the highest exposure category showed a sevenfold higher risk of having HRCT well defined round opacities than

Table 3 Association between high-resolution CT (HRCT) findings and exposure

\begin{tabular}{|c|c|c|c|c|}
\hline & & $\begin{array}{l}\text { HRCT well defined round } \\
\text { opacities, } 12 / 79 \\
\text { OR }(95 \% \mathrm{CI})\end{array}$ & $\begin{array}{l}\text { HRCT irregular and/or linear } \\
\text { opacities, } 16 / 79 \\
\text { OR (95\% CI) }\end{array}$ & $\begin{array}{l}\text { HRCT emphysema, } \\
29 / 79 \\
\text { OR (95\% CI) }\end{array}$ \\
\hline \multirow{2}{*}{$\begin{array}{l}\text { CEI } \\
\text { tertiles } \dagger\end{array}$} & $4.5-12.9$ & $1.0(0.1$ to 7.5$)$ & $1.9(0.4$ to 8.6$)$ & $0.8(0.3$ to 2.5$)$ \\
\hline & $>12.9$ & 7.1 (1.3 to 37.8 ) & $4.0(0.9$ to 17.9$)$ & $0.3(0.08$ to 1.1$)$ \\
\hline Smoking & $\begin{array}{l}\text { Current or } \\
\text { ex-smoker } \neq\end{array}$ & $0.5(0.1$ to 2.2$)$ & $2.1(0.4$ to 11.0$)$ & $10.1^{*}(1.2$ to 84.2$)$ \\
\hline $\mathrm{R}^{2} \S$ & & 0.22 & 0.08 & 0.27 \\
\hline
\end{tabular}


Table 4 Prevalence of high-resolution CT (HRCT) emphysema in smokers stratified for HRCT well defined round opacities

\begin{tabular}{llllll}
\hline & & & \multicolumn{2}{l}{ HRCT emphysema } \\
\cline { 4 - 6 } & & & No & Yes & Total \\
\hline Lifetime non-smoker & HRCT well defined round opacities & No & $10(100 \%)$ & 0 & $10(100 \%)$ \\
& & Yes & $4(100 \%)$ & 0 & $4(100 \%)$ \\
Current or ex- smoker & Total & & 14 & 0 & 14 \\
& HRCT well defined round opacities & No & $31(55.4 \%)$ & $25(44.6 \%)$ & $56(100 \%)$ \\
& & Total & $5(55.6 \%)$ & $4(44.4 \%)$ & $9(100 \%)$ \\
& & & $36(55.4 \%)$ & $29(44.6 \%)$ & $65(100 \%)$ \\
\hline
\end{tabular}

those exposed to the lowest level. The association was independent of smoking. Simultaneously, a strong association of round opacities with pleural changes, described as aggregates of sub-pleural silicotic nodules, was found. Although it has been known for many years that some respiratory diseases are associated with pneumoconiosis (silicosis), very few studies have quantified the association of dust exposure with HRCT findings. ${ }^{11} 12$ This could be due to differences in outcome definition or to the complexity of measuring exposure to respiratory crystalline silica dust and calculating job-exposure matrices. Although the CEI, as used in our study, is a somewhat crude proxy of cumulative exposure and may be subject to substantial exposure misclassification, comparison with other studies showed reliable estimates of cumulative quartz exposure, as has been extensively discussed by Tjoe $\mathrm{Nij}^{10}$

The presence of all types of emphysema on HRCT was clearly associated with smoking and could not be attributed to cumulative quartz exposure, in that current as well as former smokers had an approximately 10-fold higher risk of having emphysema. The readers sometimes commented that different types of emphysema had a different appearance, and they were, therefore, not separately analysed.

Emphysema was detected in approximately 39\% of construction workers classified as ILO $<1 / 1$, and was only found in workers who were smokers or had smoked previously. Lifetime never smokers showed no emphysema. We also found that in ever smoking individuals, emphysema was about equally distributed between workers with and without well defined round opacities (table 4) or with and without irregular and/or linear opacities (data not shown). Therefore, our study supports the evidence that low grade pneumoconiosis is not associated with emphysema.

No association with smoking was identified for HRCT irregular and/or linear opacities. In addition, no difference in age was found between workers with and without irregular and/or linear opacities ( 50.7 years vs 49.3 years, respectively). The presence of irregular and/or linear opacities has been shown to be a troublesome confounding factor in epidemiological studies in dust exposed working populations. ${ }^{13}$ Some studies included both small irregular and small rounded opacities as representing silicosis in workers who were occupationally exposed to silica. Others included only small rounded opacities as representing silicosis. ${ }^{14}$ However, there is substantial evidence that small irregular and/or linear opacities are associated with factors such as age, cigarette smoking and workplace dust exposures (eg, asbestos, coal and diatomaceous earth). Although we found no evidence of associations with smoking and age, a borderline statistically significant association with higher dust levels and small irregular and/or linear opacities (OR 4.0) was found.

We confirmed the greater sensitivity of HRCT in detecting small parenchymal changes, emphysema and pleural abnormalities in workers whose $\mathrm{x}$-rays can be considered normal (ILO profusion category $0 / 0$ ). These findings indicate that a substantially higher rate of low grade pneumoconiosis (silicosis, asbestosis) may be expected in dust exposed construction workers, as is reported in other studies. ${ }^{15-18}$

Associations between reduced lung function and pneumoconiosis (more specifically silicosis) and emphysema have been described in different studies and reviewed by Gamble et al and Hnizdo et al. ${ }^{1920}$ The studies indicate that reduced lung function was more likely to be associated with higher categories of silicosis (ILO 3) than with lower categories and that in the absence of pulmonary massive fibrosis (PMF) no significant emphysema is attributable to silicosis. ${ }^{21}$ These findings are complicated by the fact that the majority of patients with silicosis are also smokers (current and former). Therefore, control for smoking in the analyses is mandatory to distinguish the effects of emphysema on lung function from the effects of silicosis on lung function.

We found no reduction in lung function in workers with suspected low grade silicosis (HRCT well defined round opacities) independent of emphysema or being a current smoker. In contrast, our study showed a strong association of current smoking with a reduced $\mathrm{FEV}_{1} / \mathrm{FVC}$ ratio and an increase in the RV/TLC ratio independent of the HRCT findings. The results stress the impact of current smoking on reduced lung function and may be regarded as functional impairment suggestive of airflow limitation.

Table 5 Association of high-resolution CT (HRCT) findings and current smoking with lung function (\% predicted)

\begin{tabular}{|c|c|c|c|c|c|c|c|c|c|c|c|c|}
\hline \multirow[b]{2}{*}{ HRCT } & \multicolumn{2}{|l|}{ FVC } & \multicolumn{2}{|l|}{ FEV $_{1}$} & \multicolumn{2}{|l|}{$\mathrm{FEV}_{1} / \mathrm{FVC}$} & \multicolumn{2}{|l|}{ TLC } & \multicolumn{2}{|l|}{ RV/TLC } & \multicolumn{2}{|l|}{$T_{L, c o, s b}$} \\
\hline & $\begin{array}{l}\beta \text { Coefficient } \\
\text { (SE) }\end{array}$ & $\begin{array}{l}p \\
\text { Value }\end{array}$ & $\begin{array}{l}\beta \text { Coefficient } \\
\text { (SE) }\end{array}$ & $\begin{array}{l}p_{\text {Value }} \\
\text { Val }\end{array}$ & $\begin{array}{l}\beta \text { Coefficient } \\
\text { (SE) }\end{array}$ & $\begin{array}{l}\mathbf{p} \\
\text { Value }\end{array}$ & $\begin{array}{l}\beta \text { Coefficient } \\
\text { (SE) }\end{array}$ & $\begin{array}{l}p_{\text {Value }} \\
\text { Val }\end{array}$ & $\begin{array}{l}\beta \text { Coefficient } \\
\text { (SE) }\end{array}$ & $\begin{array}{l}\mathbf{p} \\
\text { Value }\end{array}$ & $\begin{array}{l}\beta \text { Coefficient } \\
\text { (SE) }\end{array}$ & $\begin{array}{l}\mathbf{p} \\
\text { Value }\end{array}$ \\
\hline $\begin{array}{l}\text { Well defined round } \\
\text { opacities }\end{array}$ & $5.6(3.9)$ & 0.16 & $3.1(4.3)$ & 0.5 & $-1.5(2.9)$ & 0.6 & $2.0(3.2)$ & 0.5 & $-5.7(3.2)$ & 0.07 & $-6.3(3.5)$ & 0.17 \\
\hline $\begin{array}{l}\text { Irregular and/or linear } \\
\text { opacities }\end{array}$ & $-10.5(3.5)$ & 0.004 & $-11.6(3.9)$ & 0.004 & $-1.9(2.6)$ & 0.5 & $-5.1(2.8)$ & 0.08 & $7.4(2.8)$ & 0.01 & $-8.1(4.0)$ & 0.05 \\
\hline Emphysema & $-4.0(3.2)$ & 0.22 & $-7.9(3.5)$ & 0.03 & $-4.0(2.4)$ & 0.09 & $-1.4(2.6)$ & 0.6 & $1.3(2.6)$ & 0.6 & $-9.6(3.7)$ & 0.01 \\
\hline $\mathrm{R}^{2}$ & 0.14 & & 0.24 & & 0.18 & & 0.13 & & 0.26 & & 0.34 & \\
\hline
\end{tabular}

$\mathrm{FEV}_{1}$, forced expiratory volume in $1 \mathrm{~s}$; FVC, forced vital capacity; RV, residual volume; TLC, total lung capacity; $\mathrm{T}_{\mathrm{L}, \mathrm{Co}, \mathrm{sb}}$, single-breath carbon monoxide transfer factor. 
Individuals with HRCT irregular and/or linear opacities showed reduced FVC and $\mathrm{FEV}_{1}$ values, and a small (8\%) reduction in diffusion capacity $\left(\mathrm{T}_{\mathrm{L}, \mathrm{CO}, \mathrm{sb}}\right)$ at a statistically significant level. However, the poor agreement of the readers for irregular and/or linear opacities make these findings controversial and therefore unreliable.

Current smoking was shown to be the major determinant for bronchial obstruction (reduced $\mathrm{FEV}_{1} / \mathrm{FVC}$ ratio) in our study and is accompanied by an increased RV/TLC ratio. Reduced diffusion capacity was shown to be associated with current smoking and with emphysema. This finding supports the evidence from other studies in which emphysema contributes to diffusion impairment. We adjusted for current smoking for two reasons; first, smoking influenced the single-breath carbon monoxide transfer factor $\left(\mathrm{T}_{\mathrm{L}, \mathrm{CO}, \mathrm{sb}}\right)$ if workers were unwilling to stop smoking before the test was performed, and second, emphysema is known to be strongly associated with past smoking. Therefore, to disentangle this association we used current smoking as a potential confounding variable in the analysis of lung function.

Our results differ slightly from the conclusions presented by Gevenois et al who found that bronchus obstruction and impairment in diffusion capacity $\left(\mathrm{D}_{\mathrm{L}}, \mathrm{co}\right)$ was associated with emphysema and not with micronodules detected by CT scans in workers seeking compensation. ${ }^{22}$

In contrast to their results, we found a substantial effect of current smoking on bronchial obstruction and a reduced diffusion capacity associated with both smoking and emphysema. Consistent with their results, we found no association of round opacities and irregular and/or linear opacities with smoking, a finding not in agreement with that of Collins et al ${ }^{23}$ Although their analyses did not differentiate for round and irregular opacities, our study indicates that irregular and/or linear opacities may be associated with reduced diffusion capacity.

To summarise, our results should be interpreted with care because of the small size of the study population and potential responder bias due to $47 \%$ of construction workers declining the invitation to participate. Error in exposure estimation may play a role because retrospective exposure assessment is subject to misclassification. In addition, construction workers are exposed to various chemicals and other minerals. Error in HRCT outcome is expected to be minor. The readers were trained and agreement was high, except for the presence of irregular and/or linear opacities. Nevertheless, we think it can be concluded that a normal chest radiograph (ILO 0/0) does not exclude the presence of low grade silicosis. Consequently, the prevalence of pneumoconiosis (silicosis) among Dutch construction workers, as estimated in the earlier study, may be higher than previously thought. In relatively highly exposed construction workers, a sevenfold increased risk of simple (nodular) silicosis was found. The risk of emphysema was 10-fold higher in current and exsmokers, was not associated with exposure and contributed to reduced diffusion capacity. No emphysema was detected in never smokers. Reduced lung function indicative of airflow limitation was mainly determined by current smoking. Our study supports the already documented exposure-response relationship between silica dust exposure and silicosis in construction workers, in that well defined round opacities on HRCT are clearly associated with relatively high quartz exposure in workers.

Acknowledgements The authors would like to thank the participants who volunteered for this study. Mireille van der Drift is highly appreciated for her contribution to the fieldwork. For the readings of the HRCT scans we acknowledge the support of the radiologists Dr KG Hering (Head of the Department of Diagnostic Radiology, Knappschaftskrankenhaus, Dortmund, Germany) and Dr HG Hieckel (Head of the Department of Diagnostic Radiology, Clinic and Outpatient Clinic for Lung Diseases, Berlin, Germany). The 'B' readings were organised by Mike Attfield from NIOSH and performed by Dr Jack Parker, Dr Ralph Shipley and Dr George Delclos. The accuracy of the lung function measurements is due to the knowledge and enthusiasm of Niesje Verheij, Erica Dijkers, Dr Carel Roos, Pieter Zanen, Paul Munnik and all lung function assistants.

Funding This project was funded by Arbouw (Harderwijk, the Netherlands), a Dutch institute for occupational health and safety in the construction industry.

\section{Competing interests None.}

Ethics approval This study was conducted with the approval of the medical ethics committees of the Academic Medical Center Amsterdam and University Medical Center Utrecht.

Provenance and peer review Not commissioned; externally peer reviewed.

\section{REFERENCES}

1. ILO. Guidelines for the Use of ILO International Classification of Radiographs of Pneumoconiosis. 2000 edn. Geneva: International Labour Office, 2002 (Occupational Safety and Health Series, No 22 (rev 2000).

2. Tjoe Nij E, Burdorf A, Parker J, et al. Radiographic abnormalities among construction workers exposed to quartz containing dust. Occup Environ Med 2003:60:410-17.

3. Bergin CJ, Muller NL, Vedal S, et al. CT in silicosis: correlation with plain films and pulmonary function tests. AJR 1986;146:477-83.

4. Remy-Jardin M, Degreef JM, Beuscart R, et al. Coal worker's pneumoconiosis: CT assessment in exposed workers and correlation with radiographic findings. Radiology 1990;177:363-71.

5. Mosiewicz J, Myslinski W, Zlomaniec G, et al. Diagnostic value of high resolution computed tomography in the assessment of nodular changes in pneumoconiosis in foundry workers in Lublin. Ann Agric Environ Med 2004;11:279-84.

6. Medical Research Council Committee on the Aetiology of Chronic Bronchitis. Standardized questionnaire on respiratory symptoms. Br Med J 1960:2:1665.

7. Hering KG, Tuengerthal S, Kraus T. Standardized CT/HRCT-classification of the German Federal Republic for work and environmental related thoracic diseases. Radiologe 2004;44:500-11.

8. Suganuma N, Kusaka Y, Hering KG, et al. Reliability of the proposed international classification of high-resolution computed tomography for occupational and environmental respiratory diseases. J Occup Health 2009:51:210-22.

9. Quanjer PH, Tammeling GJ, Cotes JE, et al. Lung volumes and forced ventilatory flows. Report Working Party Standardization of Lung Function Tests, European Community for Steel and Coal. Official Statement of the European Respiratory Society. Eur Respir J Supp/ 1993;16:5-40.

10. Tjoe Nij E, Borm P, Höhr D, et al. Pneumoconiosis and exposure to quartz-containing dust in the construction industry. Ann Occup Hyg 2002;46:71-5.

11. Antão VC, Pinheiro GA, Kavakama J, et al. High prevalence of silicosis among stone carvers in Brazil. Am J Ind Med 2004:45:194-201.

12. Paris C, Benichou J, Raffaelli C, et al. Factors associated with early-stage pulmonary fibrosis as determined by high-resolution computed tomography among persons occupationally exposed to asbestos. Scand J Work Environ Health 2004;30:206-14.

13. Dick JA, Morgan WK, Muir DF, et al. The significance of irregular opacities on the chest roentgenogram. Chest 1992;102:251-60.

14. Hessel PA, Gamble JF, Nicolich M. Relationship between silicosis and smoking Scand J Work Environ Health 2003;29:329-36.

15. Savranlar A, Altin R, Mahmutyazicioglu K, et al. Comparison of chest radiography and high-resolution computed tomography findings in early and low-grade coal worker's pneumoconiosis. Eur J Radiol 2004:51:175-80.

16. Lamers RJ, Schins RP, Wouters EF, et al. High-resolution computed tomography of the lungs in coal miners with a normal chest radiograph. Exp Lung Res 1994:20:411-19.

17. Hnizdo E, Murray J, Sluis-Cremer GK, et al. Correlation between radiological and pathological diagnosis of silicosis: an autopsy population based study. Am J Ind Med 1993:24:427-45

18. Sun J, Weng D, Jin C, et al. The value of high resolution computed tomography in the diagnostics of small opacities and complications of silicosis in mine machinery manufacturing workers, compared to radiography. J Occup Health 2008;50:400-5.

19. Gamble JF, Hessel PA, Nicolich M. Relationship between silicosis and lung function Scand J Work Environ Health 2004;30:5-20.

20. Hnizdo E, Vallyathan V. Chronic obstructive pulmonary disease due to occupationa exposure to silica dust: a review of epidemiological and pathological evidence. Occup Environ Med 2003;60:237-43

21. Kinsella M, Mèuller N, Vedal S, et al. Emphysema in silicosis: a comparison of smokers with non-smokers using pulmonary function testing and computed tomography. Am Rev Respir Dis 1990;141:1497-500.

22. Gevenois PA, Sergent G, De Maertelaer V, et al. Micronodules and emphysema in coal mine dust or silica exposure: relation with lung function. Eur Respir J 1998;12:1020-4

23. Collins LC, Willing S, Bretz R, et al. High-resolution CT in simple coal workers pneumoconiosis. Lack of correlation with pulmonary function tests and arterial blood gas values. Chest 1993;104:1156-62. 